\title{
The effects of saline toxicity and food-based AD digestate on the earthworm Allolobophora chlorotica
}

by Natalio, A.I., Back, M., Richards, A. and Jeffery, S.

Copyright, publisher and additional Information: This is the author accepted manuscript. The final published version (version of record) is available online via Elsevier.

This version is made available under the $\underline{\text { CC-BY-ND-NC licence }}$

Please refer to any applicable terms of use of the publisher

DOI link to the version of record on the publisher's website 


\section{The effects of saline toxicity and food-based AD digestate on the \\ 2 earthworm Allolobophora chlorotica}

4 Authors: Natalio, Ana IM*1; Back, Mathew ${ }^{1}$; Richards, Andrew ${ }^{2}$; Jeffery, Simon ${ }^{1}$

6 * Corresponding author: amoraisnatalio@harper-adams.ac.uk

$8{ }^{1}$ Agriculture and Environment, Harper Adams University, Newport, Shropshire 9 TF10 8NB, UK

102 Masstock Arable (UK) Ltd., Andoversford, Cheltenham, GL54 4LZ, UK

12 Abstract

14 Anaerobic digestion (AD) is used to produce biogas and can offer a solution in

15 waste management. Digestate, the AD by-product, can be applied to soil to

16 improve fertility. However, the response of soil biological communities is not fully

17 understood. There are mixed reports on its impact on earthworm survival. This

18 study aimed to investigate digestate effects on earthworm mortality, and to

19 elucidate potential mechanisms underlying it, if observed, after digestate

20 application to soil. Juvenile and adult Allolobophora chlorotica were used as model

21 organisms and added to microcosms prepared in a glasshouse trial. Five

22 replicated treatments were: liquid Digestate; Osmotic-Stress (i.e. same salt

23 concentration as digestate); Labile-C (i.e. same Biological Oxygen demand as

24 Digestate); Synthetic-Digestate a mixture of Osmotic-Stress and Labile-C (i.e.

25 same salt concentration and BOD as digestate); and Water as the control.

26 Treatments were applied at two different standardised rates equivalent to the

27 digestate's $\mathrm{N}$ content (i.e. $150 \mathrm{~kg} \mathrm{~N} \mathrm{ha}^{-1}$ eq. or $300 \mathrm{~kg} \mathrm{~N} \mathrm{ha}^{-1}$ eq.). The two

28 development stages of $A$. chlorotica had different responses to treatments. Adult 
29 biomass was significantly greater in the Water control R150 treatment than in

30 Digestate. Significantly lower juvenile biomass was observed in the Digestate

31 R300 treatment than in the Labile-C and Water control treatments. The biomass of

32 adults in the Labile-C R300 treatment was significantly greater than in the

33 Digestate, Osmotic-Stress, Synthetic-Digestate and Water control treatments.

34 Both life-stages exhibited a decline in biomass across all treatments, but the adults

35 had higher mortality rates. The biomass of adults and juveniles declined,

36 respectively, by $90 \%$ and $62 \%$ for Digestate applied at the lower rate, and by 96

$37 \%$ and $90 \%$ at the higher rate. Whereas the abundance of adults and juveniles

38 suffered $80 \%$ and $24 \%$ drop at the lower rate, and a $90 \%$ and $84 \%$ drop at the

39 higher rate. This study demonstrates that digestate can have negative impact on

40 earthworm morbidity and mortality when applied to soil at $60 \%$ water filed pore

41 space, with most of the total weight loss per pot due to reduced earthworm

42 abundance. A likely hypothesis could be the osmotic stress induced by salts

43 present in the digestate. However, there are other factors that interact with this

44 effect, including possibly anaerobic impacts caused by high water content soils, as

45 well as other mechanisms that have not been fully elucidated through this

46 experimental design. Nevertheless, this work provides the basis for further

47 ecotoxicology studies on the impact of digestate applied to soil. Further, while this

48 works has shown that digestate can negatively impact $A$. chlorotica survival,

49 whether the same is true for other earthworm species, ecotypes and life-cycle

50 stages warrants further investigation. Considering the important role that worms

51 play in soil health, field scale studies are also required to monitor the impacts of

52 repeated digestate application on earthworm communities. 
54 Key words: Lumbricidae; ecological category; toxicology; soil health; soil

55 amendments; bioindicators.

59 Earthworms are ecosystem engineers with functional roles within the soil profile

60 that affect ecological processes and properties. They modify soil properties

61 through bioturbation processes, including their burrowing and feeding action

62 (Huber et al., 2008; Ritz et al., 2009; Blouin et al., 2013). As such, they have been

63 widely used as bioindicators in soil monitoring networks and environmental

64 assessments (Huber et al., 2008).

65 Allolobophora chlorotica Savigny (Lumbricidae), is an intermediate earthworm (in

66 the epi-endo-anecic ecological category), that develops as a pale or green morph

67 (Satchell, 1967; Bottinelli et al. 2020). They are the most commonly found

68 earthworm in England, especially in neutral to base-rich grasslands and arable

69 soils, where they are usually found in the rhizosphere (Jones and Eggleton, 2014).

70 Their tolerance to various degrees of soil moisture is morph dependent, and both

71 morphs can be found in different soil types of $\mathrm{pH}$ ranging from 4.5-8.2 (Satchell,

72 1967; Sims and Gerard, 1999). They create horizontal burrows and excrete casts,

73 usually within the soil rather than on the surface. Earthworm casts are rich in plant

74 available nutrients (Lee, 1985; Vos et al., 2014) and their feeding action can

75 facilitate the formation of soil aggregates (Kavdir and Ilay, 2011).

76 Soil organisms known to be beneficial ecosystem engineers like earthworms are

77 often used in toxicity studies. These studies generally rely on commercially

78 available epigeic and anecic earthworms. However, these are not best suited to

79 soil toxicity studies or for determining the impact of nutrient mobility and availability

80 (Sizmur and Hodson, 2009). For example, epigeics can be directly exposed to soil 
81 amendments but, like anecics, feed mostly on plant matter. Conversely, epi-endo-

82 anecic, such as $A$. chlorotica, are exposed to and feed on accumulated residues

83 within the soil profile and so may be better models for soil toxicity and nutrient

84 mobility studies (Van-camp et al., 2004; Sizmur et al., 2017).

85 It has been estimated that 180 million tonnes of digestate, a by-product of

86 anaerobic digestion (AD), are produced in the EU28 every year. A variety of

87 feedstocks can be used to produce energy through AD processes, such as

88 manures, crop residues, energy crops and food waste (Corden et al., 2019).

89 Digestate is mostly used as a soil amendment in agricultural systems. Its

90 composition is variable, mainly dependent on the feedstock digested. Its

91 application to land has potential environmental risks, such as ammonia emissions,

92 heavy metal contamination and/or a high salt content, and its impact on soil

93 biological communities is not well understood (Taylor et al. 2011; EA and WRAP,

94 2014; Moller, 2015; Corden et al., 2019). The impact on earthworm survival

95 following the application of food-based digestate to land has been shown to be site

96 dependent WRAP (2015); abundance reduced in some sites, whereas in others no

97 significant difference was observed. Another study found that the spreading of

98 digestate could reduce the abundance of endogeics, and that $A$. chlorotica was

99 missing from such treatment at a particular site (Koblenz et al. 2015). Sizmur et al.

100 (2017) observed an increase in the biomass of anecic earthworms following the

101 application of digestate incorporated with straw.

102 The main factors affecting digestate impacts on earthworm populations remain

103 unknown but are likely to include osmotic stress due to salts present, increased

104 anaerobicity due to digestates' biochemical oxygen demand (BOD), chemical

105 oxygen demand and $\mathrm{pH}$ impacts due to the presence of volatile fatty acids

106 (WRAP, 2015). 
107 This study aimed to elucidate mechanisms associated with the effect of BSI PAS

108110 (British Standards Institution Publicly-Available Specification) food-based

109 digestate on $A$. chlorotica survival following application to soil, and whether there

110 is a different response between the juvenile and adult stages. This was done to

111 test the following hypotheses:

112 1. Digestate application to soil increases $A$. chlorotica mortality

1132 2. Increased $A$. chlorotica mortality is caused by salt stress

114 3. Increased $A$. chlorotica mortality is caused by anaerobicity resulting from 115 the digestate application

2. Materials and Methods

\subsection{Experimental design}

121 The experiment used independent measures in a randomised block design.

122 Microcosms were constructed using $10.3 \mathrm{~L}$ white food-safe polypropylene boxes

$123(28.6 \times 19.8 \times 27.3 \mathrm{~cm})$ with six $1.5 \mathrm{~mm}$ drainage holes. The hook side of self-

124 adhesive hook \& loop tape, $2.5 \mathrm{~cm}$ wide, was attached around the internal rim of

125 each box to prevent earthworms escaping (Lubbers and van Groenigen, 2013).

126 The boxes were filled with loamy sand topsoil (80.6 \% sand, $14.2 \%$ silt, $5.2 \%$

127 clay, $3.0 \%$ SOM, pH $6.6 \mathrm{H}_{2} \mathrm{O}$ ) collected from Crabtree Leasow field, Harper

128 Adams University (HAU), UK (Latitude: 52.772627, Longitude: -2.424008) to 20

$129 \mathrm{~cm}$ depth. Soil was homogenised by removing plant material, gravel, and rocks (>

$1305 \mathrm{~mm}$ ), sieving (4 mm), passing it through a shredder (Royer Pneulec, 240v

131 soil/compost shredder) and repeated mixing using a spade. Pots were packed to a

132 dry bulk density of $1.3 \mathrm{~g} \mathrm{~cm}^{-3}$ (10.4 kg dry soil per pot) and maintained 
133 gravimetrically at $60 \%$ water filed pore space (WFPS) for the duration of the

134 experiment by watering every two days with tap-water.

135 Two adult and five juveniles of $A$. chlorotica (pale morph only) were added to each

136 box and allowed to adapt for five days before treatments were applied. The total

137 earthworm biomass did not significantly differ between replicates or across

138 treatments.

139 Ten treatments were replicated five times each to give a total of 50 experimental

140 units. Treatments were prepared to replicate the application of anaerobic digestion

141 (AD) digestate, raw liquid phase, at rates equivalent to $150 \mathrm{~kg} \mathrm{~N} \mathrm{ha}^{-1}$ and $300 \mathrm{~kg} \mathrm{~N}$

$142 \mathrm{ha}^{-1}, \mathrm{R} 150\left(16.6 \mathrm{tFW} \mathrm{ha}^{-1}\right)$ and $\mathrm{R} 300$ (33.2 tFW ha-1) respectively.

1432.2 Treatments

144

145 The AD digestate (Table 1) was collected from a plant located in Shropshire,

146 managed to British Standards Institution Publicly-Available Specification, BSI PAS

147110 (industry specification verifiable for consistent quality and fit for purpose). The

148 conditions were: Mesophilic $\left(44^{\circ} \mathrm{C}\right)$; Hydraulic Retention Time (HRT) of 40 days.

149 Feedstock: 50\% food waste from processed food factories; $40 \%$ non-animal by-

150 products (e.g. dairy derived, products of animal feed production); $7-7.5 \%$ poultry

151 litter; 2.5 - 3\% compost leachate (i.e. liquid that seeps from decomposing organic

152 material).

153 The results obtained from characterisation measurements on the digestate (i.e.

154 salinity, electrical conductivity, biological oxygen demand and $\mathrm{pH}$ ) were used to

155 develop synthetic treatments mimicking labile-carbon (C) content, salt content and

156 a mix of both salt and labile $\mathrm{C}$ in the digestate. Three solutions were produced and

157 standardised: hereafter Labile-C, Osmotic-Stress or Synthetic-Digestate,

158 respectively. 
159 Table 1: Characteristics of whole digestate, units as appropriate relative to fresh

160 matter (FM) or dry matter (DM).

\begin{tabular}{lll} 
Parameter & Units & Result \\
\hline $\mathrm{pH}$ & $\begin{array}{l}\mathrm{pH} \\
\text { units }\end{array}$ & $8.4(\mathrm{FM})$ \\
\hline Oven dry matter (TS) & $\% \mathrm{~m} / \mathrm{m}$ & $5.13(\mathrm{DM})$ \\
\hline Volatile solids (VS) & $\% \mathrm{~m} / \mathrm{m}$ & $3.13(\mathrm{DM})$ \\
\hline Total Nitrogen (N) & $\% \mathrm{~m} / \mathrm{m}$ & $0.904(\mathrm{DM})$ \\
\hline Ammoniacal Nitrogen $\left(\mathrm{NH}_{4}-\mathrm{N}\right)$ & $\mathrm{mg} \mathrm{kg}^{-1}$ & $6668(\mathrm{FM})$ \\
\hline Total Potassium (K) & $\mathrm{mg} \mathrm{kg}^{-1}$ & $4017(\mathrm{DM})$ \\
\hline Total Sodium (Na) & $\mathrm{mg} \mathrm{kg}^{-1}$ & $2869(\mathrm{DM})$ \\
\hline Total Calcium (Ca) & $\mathrm{mg} \mathrm{kg}^{-1}$ & $1686(\mathrm{DM})$ \\
\hline Total Phosphorus (P) & $\mathrm{mg} \mathrm{kg}^{-1}$ & $1359(\mathrm{DM})$ \\
\hline Total Magnesium (Mg) & $\mathrm{mg} \mathrm{kg}^{-1}$ & $157(\mathrm{DM})$ \\
\hline Biological Oxygen Demand (BOD) & $\mathrm{mg} \mathrm{L}^{-1}$ & $8720(\mathrm{FM})$ \\
\hline Electrical Conductivity (EC) at 21 ${ }^{\circ} \mathrm{C}$ & $\mathrm{mS}$ & $51.6(\mathrm{FM})$ \\
\hline
\end{tabular}

162 The Labile-C treatment consisted of a solution of glucose, L-glutamic acid and

163 starch prepared to match biological oxygen demand (BOD level of $8718 \mathrm{mg} \mathrm{L}^{-1}, \mathrm{pH}$

164 8.2, EC $19 \pm 2 \mathrm{mS}$, Temp $21 \pm 1^{\circ} \mathrm{C}$ ) obtained from the AD digestate. Biological

165 oxygen demand values provide an indication on the concentration of labile-C

166 (Taylor et al., 2011).

167 The Osmotic-Stress treatment was formulated using a saline solution comprised of

168 sodium chloride $(\mathrm{NaCl})$, potassium chloride $(\mathrm{KCl})$, calcium chloride $\left(\mathrm{CaCl}_{2}\right)$ and

169 magnesium chloride $\left(\mathrm{MgCl}_{2}\right)$ in accordance with the main ions found in the $A D$

170 digestate. The concentration ratios were replicated (i.e. $\mathrm{NaCl}: \mathrm{KCl}: \mathrm{CaCl}_{2}: \mathrm{MgCl}_{2}$,

171 19:16:9:1 $\mathrm{g} \mathrm{L}^{-1}$ ) to match digestate's electrical conductivity (EC) and $\mathrm{pH}$ adjusted

172 with hydrochloric acid $\left(\mathrm{EC}=51 \pm 2 \mathrm{mS}, \mathrm{pH}=8.4\right.$, Temp $\left.=21 \pm 1^{\circ} \mathrm{C}\right)$. Electrical 
173 conductivity provides a proxy measure for quantifying salts in soils and can be

174 used for assessing saline toxicity (Owojori and Reinecke, 2014).

175 The Synthetic-Digestate treatment was produced using the solution as of Labile-C

176 and mixing in the same concentration of salts as in the Osmotic-Stress solution

$177\left(\mathrm{EC}=47 \pm 2 \mathrm{mS}, \mathrm{pH}=8.5, \mathrm{Temp}=21 \pm 1^{\circ} \mathrm{C}\right)$. Deionized water was used as the

178 Water control treatment.

179 All treatments were applied to the soil surface, $\mathrm{R} 150$ received $100 \mathrm{ml}$ from each

180 treatment per respective replicate, and $\mathrm{R} 300$ received $200 \mathrm{ml}$, increasing WFPS to

181 c. $61 \%$. Earthworms were not provided with any food during the experiment

182 beyond the organic matter content of the treatment applied. Continuous

183 observation was done for $1 \mathrm{~h}$ post application of treatments, and subsequent

184 observations were made on the hour for six hours on the day. The worms that

185 surfaced after treatments were applied and died were collected, washed and pat-

186 dried and their mass recorded.

190 Allolobophora chlorotica were collected from a grassland site south of Shrewsbury,

191 UK (Latitude: 52.614207 ; Longitude: -2.695704 ) by digging to $20 \mathrm{~cm}$ depth and

192 hand sorting earthworm species in situ. Both colour morphs and development

193 stages were collected but only the pale morph was used in the experiment.

194 Juveniles were differentiated from other species through their characteristic curling

195 behaviour and excretion of coelomic fluid when handled (Sims and Gerard, 1999).

196 They were kept in $50 \mathrm{~L}$ plant pots filled with a composite of oven dried at $105^{\circ} \mathrm{C}$

197 soil and fresh soil from the sampled pits at a ratio of 75:25. Soil was free from

198 roots, living plants and macrofauna. Diced carrots $(\sim 180 \mathrm{~g})$, apples $(\sim 200 \mathrm{~g})$ and 
199 green beans $(\sim 100 \mathrm{~g})$ were mixed into the soil on a weekly basis. The culture was

200 kept at $18^{\circ} \mathrm{C}$, in the dark, for 3 months prior to the start of the trial (Butt and Lowe,

201 2010). This period allowed standardisation of feeding, while also ensuring that

202 earthworms were randomly applied to each treatment with no pit collection effects.

203 During experimental setup, earthworms were removed from culture, rinsed with

204 deionised water, and kept in a plastic container with moist paper towel for $24 \mathrm{~h}$ to

205 void their guts. Their mass was then recorded as each worm was placed in the 206 experiment.

207 The experiment was concluded after 29 days, at which point the soil in the boxes

208 was removed by hand, earthworms and cocoons hand sorted, and developmental

209 stages counted. Following this, earthworms were placed in moist plastic boxes for

$21024 \mathrm{~h}$ at $18^{\circ} \mathrm{C} \pm 2^{\circ} \mathrm{C}$. Excess moisture was then removed with paper towels and the

211 worms individually weighed.

212

2132.4 Soil analysis

214

215 Soil texture was determined using the pipette method (MAFF/ADAS, 1986) and

216 experimental boxes were packed with it.

217 Soil was collected at the end of trial from different depths (increments of $\sim 5 \mathrm{~cm}$ )

218 during hand sorting to obtain a representative sample. Each sample was

219 homogenised by passing it through a $4 \mathrm{~mm}$ sieve before air drying at $30^{\circ} \mathrm{C}$. The

220 exchangeable fraction of soil cations was analysed because it gives an indication

221 of their bioavailability. An aliquot of soil from the composite sample was collected

222 and analysed for $\mathrm{Na}^{+}, \mathrm{K}^{+}, \mathrm{Mg}^{2+}$ and $\mathrm{Ca}^{2+}$ ions by extracting with $1 \mathrm{M}$ ammonium

223 nitrate $\left(\mathrm{NH}_{4} \mathrm{NO}_{3}\right), 1: 5$ ratio of soil to $\mathrm{NH}_{4} \mathrm{NO}_{3}$ horizontally shaken for 30 minutes

224 and filtered through Whatman No. 2 filter paper (MAFF/ADAS, 1986). Their 
225 exchangeable fraction was analysed by inductively coupled plasma mass

226 spectrometry ICP-MS (Perkin Elmer NexION 2000). Total nitrogen (tN) content in

227 soil was analysed by combustion $\left(950^{\circ} \mathrm{C}\right)$ using Leco FP528. Soil bioavailable

228 phosphorus was extracted using the Olsen-P method (MAFF/ADAS, 1986) using

$2290.5 \mathrm{M}$ sodium bicarbonate solution adjusted to $\mathrm{pH} 8.5$ at $20^{\circ} \mathrm{C}$. Absorbance of the

230 final blue complex concentration was read in a spectrophotometer (Jenway 6305)

231 at $880 \mathrm{~nm}$.

232 Soil organic matter was determined by loss-on-ignition (Lol) (MAFF/ADAS, 1986)

233 by first oven drying soil $(10 \mathrm{~g})$ at $105^{\circ} \mathrm{C}$ and then measuring the mass loss after

234 further heating at $450^{\circ} \mathrm{C}$ for $4 \mathrm{~h}$ in a furnace (Carbolite AAF1100).

$236 \quad 2.5$ Statistical analysis

237

238 Statistics were computed using R-programming (R Core Team, 2019) and

239 additional packages: 'MASS' (Venables and Ripley BD, 2002), 'car' (Fox and

240 Weisberg, 2019), 'dplyr' (Wickman et al., 2020), 'Ime4' (Bates et al., 2015), 'vegan'

241 (Oksanen et al. 2019), 'rcompanion' (Mangiafico, 2016).

242 Raw data was visualised using boxplots and outliers identified from chemical

243 analysis. The means of the identified chemical parameters were recalculated for

244 each treatment with outliers (i.e. data points more than three standard deviations

245 away from the mean) excluded. These were one data point from each of the

246 treatments applied, specifically from the Digestate (R300), Water control (R300,

247 R150), Osmotic-Stress (R300) and Labile-C (R150).

248 Data was tested for homogeneity of variance using Lavene's test and for normality

249 with Shapiro-Wilk test. Tukey's ladder transformation of data was applied if results

250 did not satisfy the necessary assumptions of linear regression. The transformed 
251 variables were: Na R150, K R300 and P R300 (transformation applied $=-1{ }^{*} \mathrm{x}^{\wedge}$ );

252 Biomass of adults R300, and juveniles and adults R150, Na R300, Mg R300 and

253 EC R300 (transformation applied $=x^{\lambda}$ ).

254 Multiple regression models were applied to continuous data, i.e. earthworm

255 biomass (juveniles or adults from the R150 or R300 treatments as the response

256 variables) and soil chemical analysis (i.e. $\mathrm{Na}, \mathrm{K}, \mathrm{Mg}, \mathrm{Ca}, \mathrm{tN}, \mathrm{P}, \mathrm{pH}, \mathrm{EC}, \mathrm{SOM}$ ) as

257 explanatory variables with treatments as the explanatory categorical data.

258 Variables were included in the model to test which mechanism, if any, explained

259 the response to treatments of either the juvenile or adult stages.

260 Simplified models were compared to initial model using ANOVA to test the

261 significance of factors set as the explanatory variables. The Akaike information

262 criterion (AIC) was used to determine whether model simplification led to the loss

263 of information.

264 One-way ANOVA was then computed with the biomass as the response variable

265 with treatments as the explanatory variable. Tukey Honest Significant Difference

266 post-hoc tests were computed on significant models $(<0.05)$ for all individual

267 comparisons.

268 A Generalised Linear Model (GLM) using a quasi-Poisson error structure test was

269 used for count data (i.e. earthworm abundance of adults or juveniles as the

270 response variables).

271 3. Results

272

273 3.1 Earthworm Biomass Response to Treatments

274 
275 The combined initial biomass of both juvenile and adult stages before they were

276 added to boxes did not differ across treatments applied at R150 lower rate $(p=$

277 1.0, ANOVA) or R300 higher rate ( $p=0.9$, ANOVA).

278 Earthworm biomass at the end of the experiment significantly declined compared

279 to initial biomass for both stages at both application rates, R150 (juveniles $p<$ 2800.001 , adults $p<0.001$ ) or R300 (juveniles $p<0.001$, adults $p<0.001$ ), across all

281 treatments, including the Water control (Fig. 1). The biomass of adults and

282 juveniles declined, respectively, by $90 \%$ and $62 \%$ for Digestate applied at the 283 lower rate, and by $96 \%$ and $90 \%$ at the higher rate.

284 The concentration of salts (as the covariate in the model) did not explain biomass

285 decline of juveniles (as response variable) when compared to the Water control 286 treatments (as explanatory variables) that were either added at $\mathrm{R} 150$ rate $(\mathrm{Na} \mathrm{p}=$ $2870.7, \mathrm{~K} p=0.6, \mathrm{Mg} \mathrm{p}=0.7, \mathrm{Ca} \mathrm{p}=0.8)$ or $\mathrm{R} 300(\mathrm{Na} p=0.7, \mathrm{~K} p=0.6, \mathrm{Mg} p=0.7$, 288 Ca $p=0.8)$. Additionally, salt concentration did not explain biomass loss of adults 289 as response variable in the $\mathrm{R} 150$ treatments $(\mathrm{Na} \mathrm{p}=0.9, \mathrm{Kp}=0.5, \mathrm{Mg} \mathrm{p}=0.3, \mathrm{Ca}$ $290 \mathrm{p}=0.2)$ or R300 treatments $(\mathrm{Na} p=0.7, \mathrm{~K} p=0.1, \mathrm{Mg} p=1.8, \mathrm{Ca} p=0.4)$.

291 Treatments' electrical conductivity (EC) (explanatory variables and respective 292 covariates) was also not able to explain biomass (as the response variable) loss in 293 comparison with Water's EC, regardless whether it was from the lower rate R150 294 treatments (Digestate: juveniles $p=0.9$ or adults $p=0.9$; Labile-C: juveniles $p=$ 2951.0 or adults $p=0.6$; Osmotic-Stress: juveniles $p=0.9$ or adults $p=0.8$; Synthetic296 Digestate: juveniles $p=0.9$ or adults $p=0.9$ ) or the higher R300 rate (Digestate: 297 juveniles $p=0.4$ or adults $p=0.4$; Labile-C: juveniles $p=0.6$, adults $p=0.5$;

298 Osmotic-Stress: juveniles $p=0.3$, adults $p=0.9$; Synthetic-Digestate: juveniles $p=$ 2990.9 , adults $p=0.5)$. 
300 Biomass was not significantly affected when multiple regression was conducted to

301 compare R300 treatments with the Water control, using SOM (juveniles $p=0.1$ or

302 adults $p=0.5$ ), $t \mathrm{~N}$ (juveniles $p=0.2$ or adults $p=0.8$ ) and $P$ (juveniles $p=0.6$ or

303 adults $p=0.7$ ) as explanatory variables. Similar analyses with the R150 rate

304 indicated that SOM (juveniles $p=0.8$ or adults $p=0.3$ ), $\mathrm{tN}$ (juveniles $p=0.9$ or

305 adults $p=0.5$ ) and $P$ (juveniles $p=0.9$ or adults $p=0.2$ ) had no effect on

306 biomass.

307 ANOVA was run with the final biomass of juveniles $(p=0.001)$ or adults $(p<0.001)$

308 (end of experiment) as the responsive variables and R300 treatments as the

309 explanatory variables. Post-hoc test revealed that the biomass of juveniles was

310 significantly greater in the Labile-C $(p=0.002)$ and Water control $(p=0.001)$ than

311 in the Digestate R300 treatment. Whereas the biomass of adults was significantly

312 greater in the Labile-C R300 treatment than Digestate $(p<0.001)$, Water control ( $p$

$313<0.001)$, Osmotic-Stress $(p=0.01)$ and Synthetic-Digestate $(p<0.001)$ R300

314 treatments. Moreover, significantly lower biomass was observed in the Synthetic-

315 Digestate treatment in comparison with Osmotic-Stress $(p=0.04)$. No significant

316 difference in biomass of juveniles between the treatments applied at the lower rate

$317 \mathrm{R} 150(p=0.68)$. In contrast, post-hoc test from the R150 treatments found that adult

318 biomass was significantly greater in the Water control than in Digestate $(p=0.03)$. 


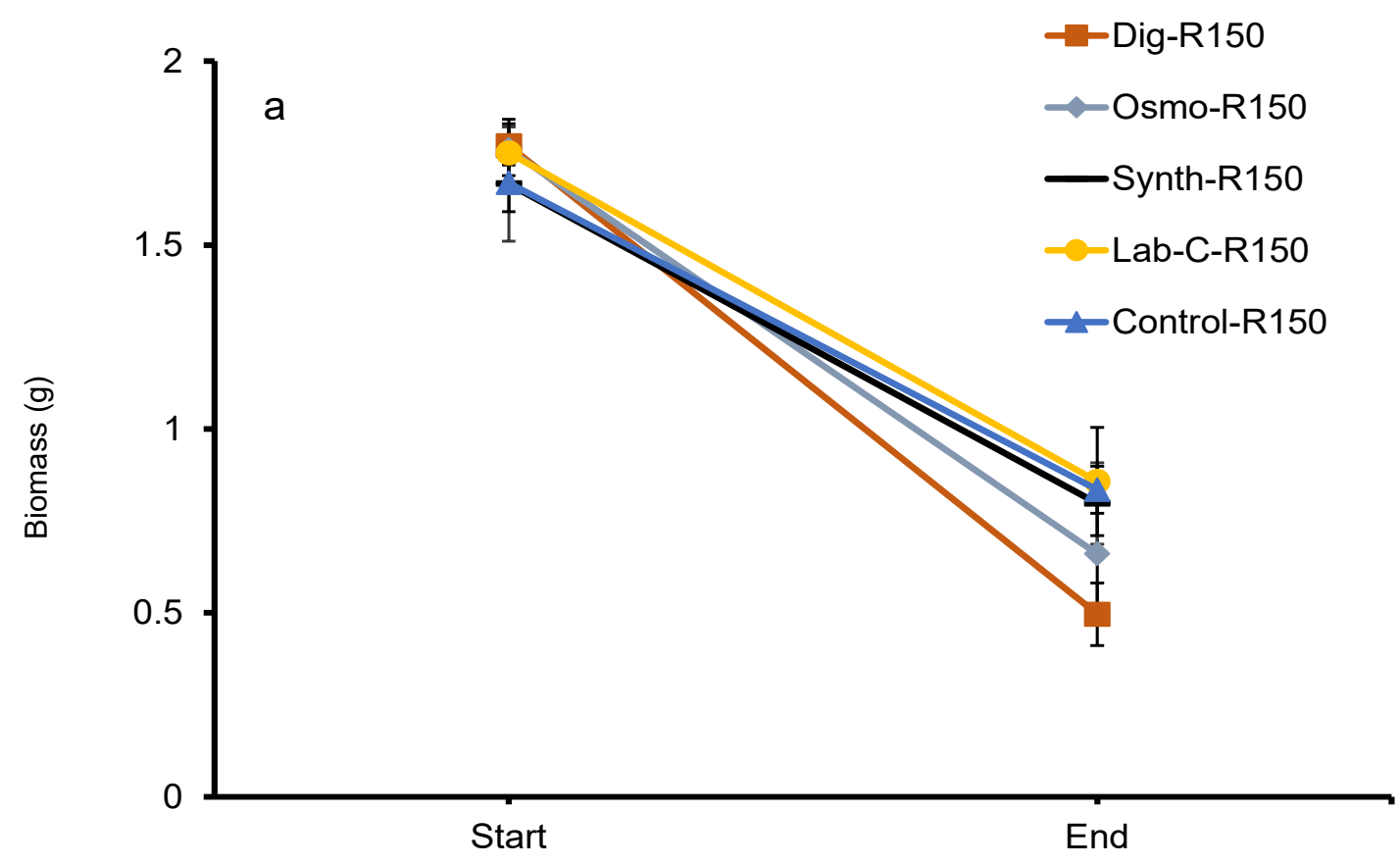

334

335

336

337

338

339

340

341

342

343

344

345

346

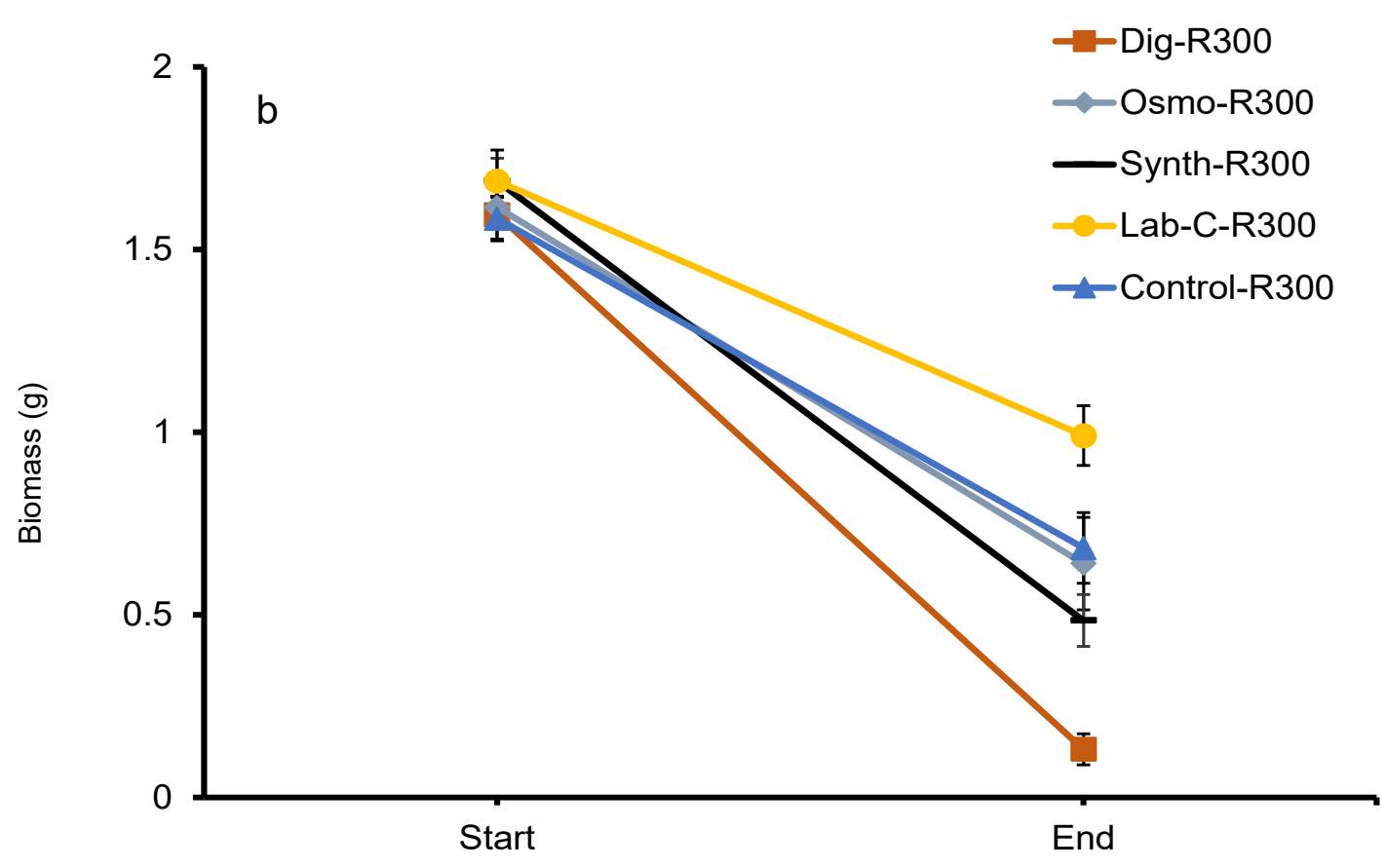

347 
348 Figure 1: Allolobophora chlorotica total mean biomass of combined juvenile and

349 adult stages at the start of the experiment before treatments were applied and at

350 the end. Biomass is grouped by treatments applied at either the lower rate (R150, 351 panel $a, p<0.001)$ or higher rate (R300, panel $b, p<0.001)$. Treatments are: Dig$352 \mathrm{Rx}=$ Digestate; Osmo-Rx = Osmotic-Stress-Rx; Synth-Rx = Synthetic-Digestate$353 \mathrm{Rx}$; Lab-C-Rx = Labile-C-Rx; Control-Rx = Water-Rx. \pm Standard error of the mean 354 (SEM)s, $\mathrm{n}=5$.

355

356 
359 The Digestate, Osmotic-Stress and Synthetic-Digestate salt containing treatments

360 resulted in some earthworms surfacing and dying shortly after these were applied

361 at both R150 ( $p=0.1)$ or R300 rates $(p<0.001)$ (Table 2$)$. Only one cocoon per

362 each R150 treatment was found at the end of the experiment, except in the Labile-

363 C treatment where none were found. In the R300 treatments, only one or two

364 cocoons were found in the Synthetic-Digestate or Labile-C treatments,

365 respectively (Table 2). No significant differences between the number of dead

366 earthworms or cocoons were found between the Digestate treatment applied at

367 either R150 or R300 rate and Osmotic-Stress $(R 150$, dead $p=0.7$, cocoon $p=$

368 1.0; R300, dead $p=1.0$, cocoon $p=1.0)$, Synthetic-Digestate $(R 150$, dead $p=0.3$,

369 cocoon $p=1.0 ; R 300$, dead $p=0.1$, cocoon $p=0.9)$, Labile-C $(R 150$ dead $p=1.0$,

370 cocoon $p=0.9 ; R 300$ dead $p=1.0$, cocoon $p=0.9)$ or Water control $(\mathrm{R} 150$ dead

$371 p=1.0$, cocoon $p=1.0 ; R 300$ dead $p=1.0$, cocoon $p=1.0$ ).

372 The overall abundance of earthworms declined at the end of the experiment

373 regardless of life stage, juveniles or adults, (R150 juveniles $p<0.001$, adults $p<$

3740.001 ; R300 juveniles $p<0.001$, adults $p<0.001$; Fig. 2 ) as determined by the

375 generalised linear models. The abundance of adults and juveniles suffered $80 \%$

376 and $24 \%$ drop at the lower rate, and a $90 \%$ and $84 \%$ drop at the higher rate.

378 The concentration of salts in the R150 treatments could not explain the decline in

379 abundance of juvenile ( $\mathrm{Na} \mathrm{p}=0.07, \mathrm{Kp}=0.07, \mathrm{Mg} \mathrm{p}=0.34$ or $\mathrm{Ca} \mathrm{p}=0.07)$ or

380 adult $(\mathrm{Na} \mathrm{p}=0.64, \mathrm{Kp}=0.54, \mathrm{Mg} p=0.52$ or $\mathrm{Ca} \mathrm{p}=0.57)$. Similar results were

381 observed with the R300 treatments, both juveniles ( $\mathrm{Na} p=0.48, \mathrm{Kp}=0.42, \mathrm{Mg} p$

$382=0.84$ or $\mathrm{Ca} \mathrm{p}=0.98)$ and adult numbers $(\mathrm{Na} \mathrm{p}=0.10, \mathrm{Kp}=0.90$ or $\mathrm{Ca} \mathrm{p}=0.21)$. 
383 There was an exception with Mg in the R300 rate that showed a significant greater

384 number of adults $(p=0.02)$, but this could not be explained as a treatment effect

385 (R300 Digestate $p=1.0$, Labile-C $p=1.0$, Osmotic-Stress $p=1.0$, Synthetic-

386 Digestate $p=1.0$ ).

387 The decline in juvenile and adult numbers in the Digestate R150 and R300

388 treatments could be explained by the simpler model with treatments only as the

389 explanatory variable, respectively. The number of juveniles $(p<0.001)$ and adults

$390(p=0.03)$ were significantly lower in the Digestate treatment, applied at the rate of

391 R300 and R150 respectively, than the Water control (Table 3). Greater final

392 number of adults were observed in the Labile-C $(p=0.01)$ than in the Water

393 control R300 treatments (Table 3).

394 Electrical conductivity results of each treatment applied at either rate, R150 or

395 R300, could not explain total mean number of juveniles (R150 Digestate $p=0.6$,

396 Labile-C $p=0.5$, Osmotic-Stress $p=0.6$, Synthetic-Digestate $p=0.6 ;$ R300

397 Digestate $p=0.3$, Labile-C $p=0.8$, Osmotic-Stress $p=0.4$, Synthetic-Digestate $p$

$398=0.7)$ or adult stages at the end of the experiment (R150 Digestate $p=0.7$, Labile-

$399 \mathrm{C} p=0.5$, Osmotic-Stress $p=0.8$, Synthetic-Digestate $p=0.7 ;$ R300 Digestate $p=$

400 1.0, Labile-C $p=1.0$, Osmotic-Stress $p=1.0$, Synthetic-Digestate $p=1.0$ ). 
403
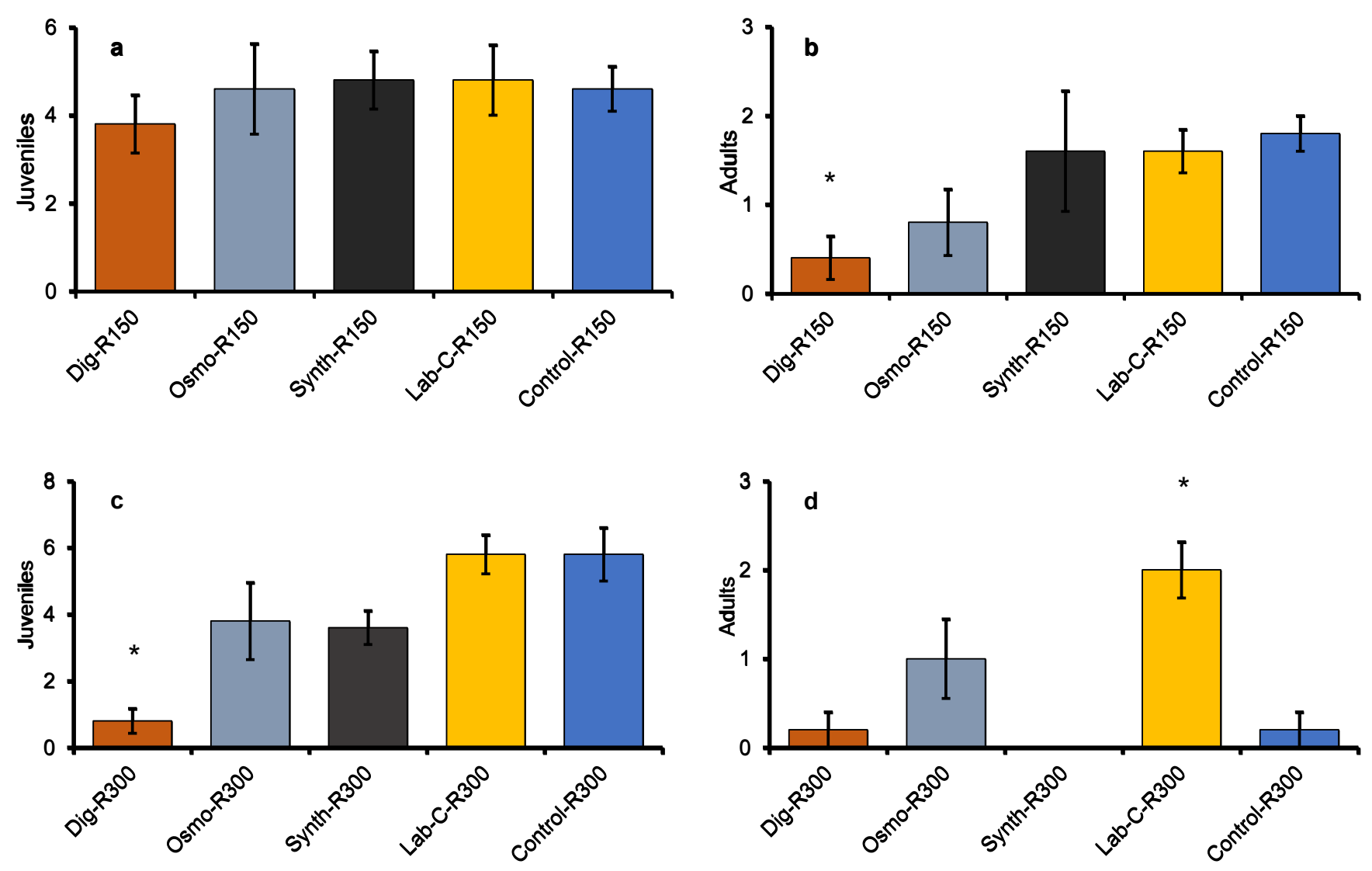

404

405 Figure 2: Mean abundance of juveniles and adults at the end of the experiment of

406 all treatments applied at the lower R150 (a \& b) and higher R300 (c \& d) rate. Dig-

$407 \mathrm{Rx}=$ Digestate; Osmo-Rx = Osmotic-Stress; Synth-Rx = Synthetic-Digestate; Lab-

408 C-Rx $=$ Labile-C; Rx $=\mathrm{R} 150$ or R300. Error bars equal Standard Error of the Mean

$409\left( \pm\right.$ SEM). Juveniles $n=5$, adults $n=2$. Asterisks $\left({ }^{*}\right)$ symbolise significantly

410 different $(p<0.05)$ results in comparison with the Water control treatment. 
412 Table 2: Total overall number of dead earthworms found at soil surface soon after

413 treatments were applied, and total cocoons at the end of trial for both lower (R150)

414 and higher (R300) rate. All treatments started with a total of seven juvenile and

415 adult earthworms per replicate, a grand total of 35 earthworm per treatment.

416

\begin{tabular}{lllll} 
& \multicolumn{3}{c}{ Rate 150 } & \multicolumn{2}{l}{ Rate 300 } \\
\cline { 2 - 5 } Treatment & Dead & Cocoons & Dead & Cocoons \\
\hline Digestate & 2 & 1 & 2 & 0 \\
\hline Labile-C & 0 & 0 & 0 & 2 \\
\hline Osmotic-Stress & 3 & 1 & 7 & 0 \\
\hline Synthetic-digestate & 5 & 1 & 7 & 1 \\
\hline Water control & 0 & 1 & 0 & 0 \\
\hline
\end{tabular}

417

418 
419 Table 3: Outputs of generalised linear models computed with the abundance of

420 either juvenile or adult stages as the response variable against treatments applied

421 at either rate as the explanatory variable. Significance of regression models was

422 set at $\leq 0.05$. Models' explained deviance (pseudo $R^{2}$ ): R150 model, juveniles $=$

$4235.8 \%$, D.F. $=20$, adults $=30 \%$, D.F. $=20 ;$ R300 model, juveniles $=57 \%$, D.F. $=$

42420, adults $=61 \%$, D.F. $=20$.

425

\begin{tabular}{|c|c|c|c|c|c|c|c|c|}
\hline \multirow[b]{3}{*}{ Intercept } & \multicolumn{2}{|c|}{ Juvenile Counts R150 } & \multicolumn{2}{|c|}{ Adults Counts R150 } & \multicolumn{2}{|c|}{ Juvenile Counts R300 } & \multicolumn{2}{|c|}{ Adults Counts R300 } \\
\hline & $\begin{array}{l}\text { Parameter } \\
\text { value }\end{array}$ & $\mathrm{P}$ & $\begin{array}{l}\text { Parameter } \\
\text { value }\end{array}$ & $\mathrm{P}$ & $\begin{array}{l}\text { Parameter } \\
\text { value }\end{array}$ & $\mathrm{P}$ & $\begin{array}{l}\text { Parameter } \\
\text { value }\end{array}$ & $\mathrm{P}$ \\
\hline & 1.53 & 0.000 & 0.59 & 0.044 & 1.76 & $<0.001$ & -1.61 & 0.060 \\
\hline Digestate & -0.19 & 0.538 & $\underline{-1.50}$ & $\underline{0.029}$ & -1.98 & $\underline{0.000}$ & 0.00 & 1.000 \\
\hline Labile-C & 0.04 & 0.884 & -0.12 & 0.771 & 0.00 & 1.000 & $\underline{2.30}$ & $\underline{0.013}$ \\
\hline $\begin{array}{l}\text { Osmotic- } \\
\text { Stress }\end{array}$ & 0 & 1.000 & -0.81 & 0.115 & -0.42 & 0.118 & 1.61 & 0.083 \\
\hline $\begin{array}{l}\text { Synthetic- } \\
\text { Digestate }\end{array}$ & 0.04 & 0.884 & -0.18 & 0.771 & -0.48 & 0.085 & -17.69 & 0.996 \\
\hline
\end{tabular}

426

427 
430 Regression analysis showed significant difference in bioavailable $\mathrm{Na}$ for the four

431 treatments in relation to the Water control treatment. Concentrations of Na were

432 greater in the Digestate $(p<0.001)$, Labile-C $(p=0.004)$, Osmotic-Stress $(p<$

$4330.001)$ and Synthetic-Digestate ( $<0.001)$ (Fig. 3).

434 Concentrations of $K$ in soil were significantly greater in the Digestate $(p=0.004)$,

435 Osmotic-Stress $(p<0.001)$ and Synthetic-Digestate $(p=0.02)$ than in the Water

436 control water treatment (Fig. 3).

437 In comparison to the Water control treatment, Mg concentrations were lower in the

438 Labile-C $(p=0.045)$, Osmotic-Stress $(p=0.04)$ and Synthetic-Digestate $(p=0.04)$ 439 (Fig. 3).

440 Concentrations of bioavailable Ca (Digestate $p=1.0$, Labile-C $p=0.4$, Osmotic-

441 Stress $p=0.5$, Synthetic-Digestate $p=0.6)$ and Olsen-P (Digestate $p=0.8$,

442 Labile-C $p=0.1$, Osmotic-Stress $p=0.7$, Synthetic-Digestate $p=0.4$ ), and SOM

443 fraction (Digestate $p=0.06$, Labile-C $p=0.6$, Osmotic-Stress $p=0.6$, Synthetic-

444 Digestate $p=0.2$ ) did not significantly differ across all treatments. The fraction of 445 total- $\mathrm{N}$ was greater in the Labile-C $(p=0.04)$ than in the Water control treatment.

446 The results of the EC were significantly higher in the Digestate $(p=0.003)$,

447 Osmotic-Stress $(p=0.005)$ and Synthetic-Digestate $(p=0.020)$ than in the Water 448 control treatment. 

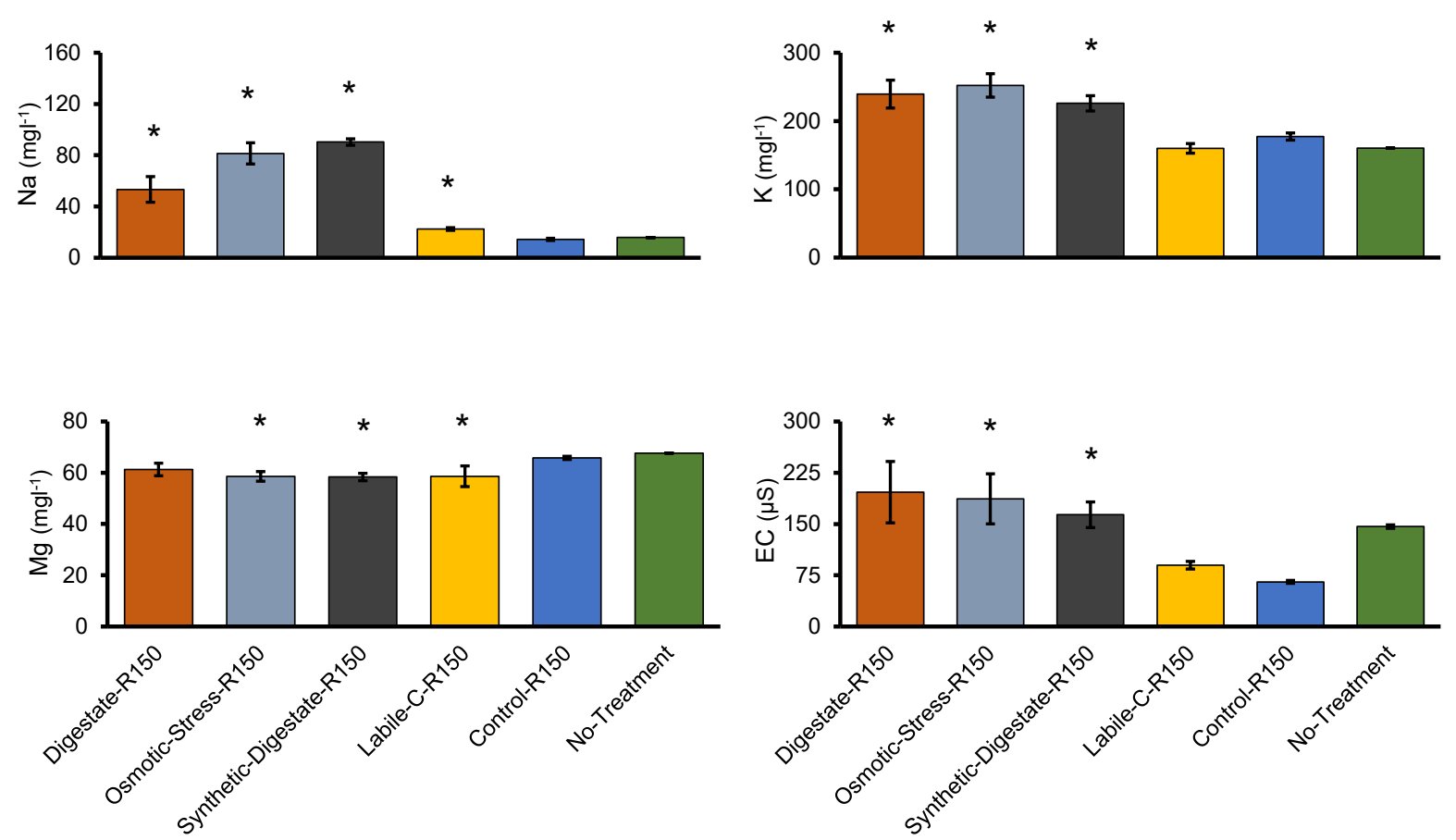

453

454 Figure 3: Concentrations of mean bioavailable $\mathrm{Na}, \mathrm{K}$ and $\mathrm{Mg}$ in soil for each

455 treatment applied at the lower rate (R150) and respective soil EC results. Initial

456 soil conditions represented by green bar (No-Treatment). $n=5, \pm$ SEM. Asterisks

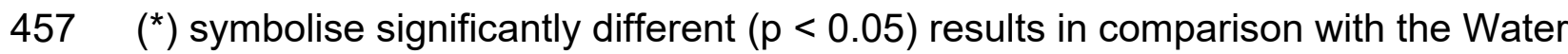

458 control treatment.

459 
462 The concentration of bioavailable $\mathrm{Na}$, at the end of the experiment, could be

463 explained by treatments containing salts. The pots that received Digestate,

464 Osmotic-Stress and Synthetic-Digestate had significantly higher concentration of 465 bioavailable $\mathrm{Na}$ in soil than the Water control $(\mathrm{p}<0.001 ; \mathrm{p}<0.001 ; \mathrm{p}<0.001$ 466 respectively). Treatments with salts also influenced bioavailable K. Significantly

467 higher soil K was observed in the Digestate $(p<0.001)$, Osmotic-Stress $(p<$ $4680.001)$, and Synthetic-Digestate $(p<0.001)$ treatments. The fraction of total- $N$ in 469 soil was significantly greater in the Synthetic-Digestate treatment $(p=0.04)$ than in 470 the Water control boxes.

471 Bioavailable $\mathrm{Mg}$ (Digestate $p=0.11$, Labile-C $p=0.31$, Osmotic-Stress $p=0.28$, 472 Synthetic-Digestate $p=0.20$ ), Ca (Digestate $p=0.15$, Labile-C $p=0.18$, Osmotic473 Stress $p=0.26$, Synthetic-Digestate $p=0.44)$, Olsen- $P($ Digestate $p=0.98$, 474 Labile-C $p=0.59$, Osmotic-Stress $p=0.06$, Synthetic-Digestate $p=0.42$ ) and 475 SOM (Digestate $p=0.42$, Labile-C $p=0.49$, Osmotic-Stress $p=0.41$, Synthetic476 Digestate $p=0.69$ ) did not differ across treatments. Olsen-P was lower in the 477 Osmotic-Stress treatment than in any other treatment but not significantly to the 478 Water control treatment $(p=0.06)$.

479 EC values were higher in pots that received the treatments of Digestate $(p<$ 480 0.001), Osmotic-Stress $(p<0.001)$ and Synthetic-Digestate $(p<0.001)$. 
484
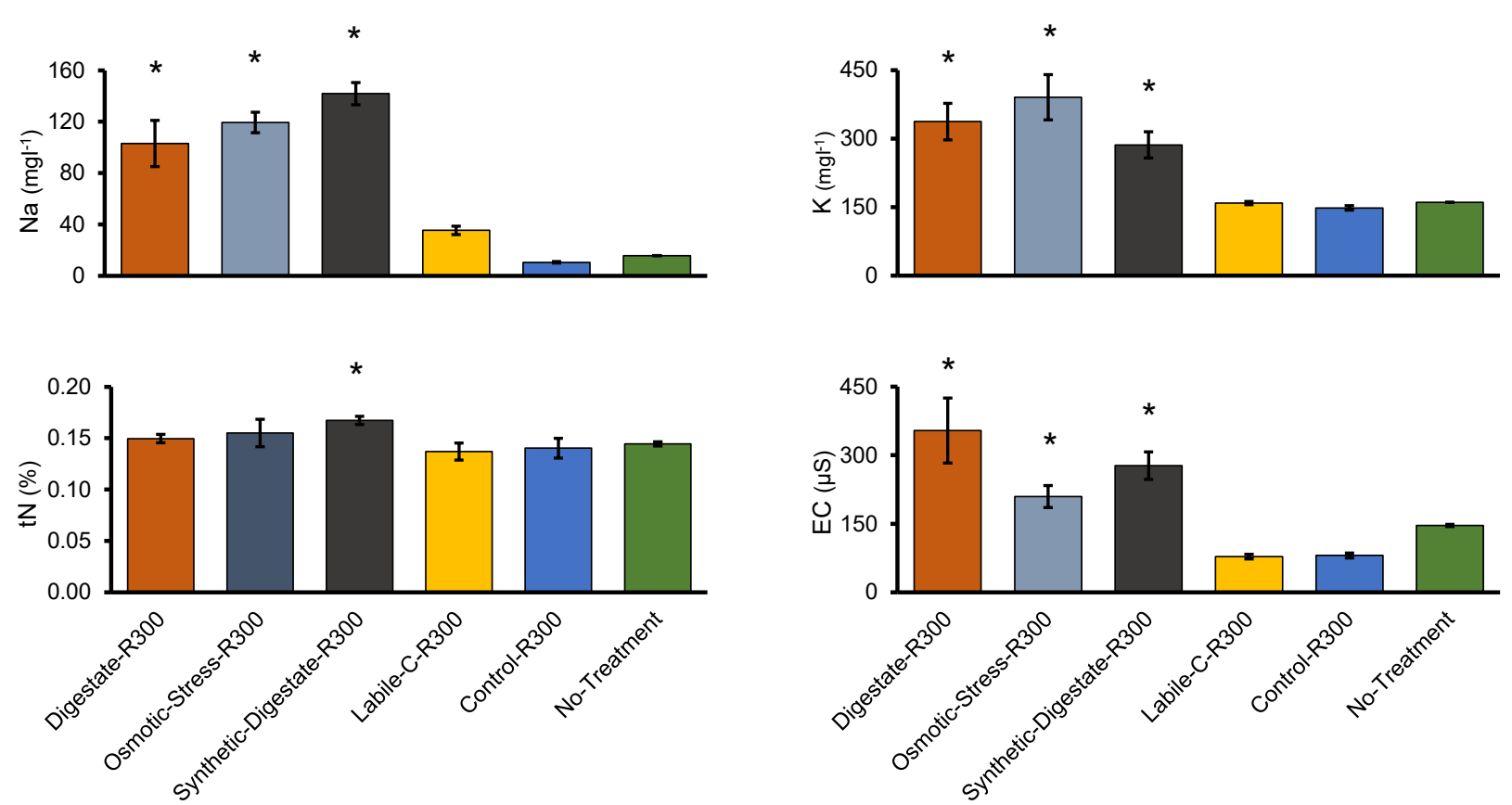

485 Figure 4: Concentrations of bioavailable $\mathrm{Na}$ and $\mathrm{K}$, and Total- $\mathrm{N}$ in soil for each

486 treatment applied at the higher rate (R300) and respective soil EC results. Initial

487 soil conditions represented by the green bar (No-Treatment). $n=5, \pm S E$.

488 Asterisks $\left(^{*}\right)$ symbolise significantly different $(p<0.05)$ results in comparison with 489 the Water control treatment.

490

491

492 
495 This study aimed to elucidate mechanisms associated with the effect of PAS 110

496 food-based digestate on A. chlorotica survival following application to soil, and

497 whether there is a different response between the adult and juvenile

498 stages. Digestate has properties that can contribute towards improving soil

499 nutrition (Wallace et al., 2011; WRAP, 2015). However, its impact on soil biological

500 communities is not fully understood. Based on the findings of this study,

501 earthworm biomass and survival may be affected by the application of digestate to

502 soil, with greater negative impacts being observed on the adult stage. Specifically,

503 a significant decline in comparison to the Water control was observed with R150

504 digestate. A-similar decline was observed for both Digestate and Water R300

505 treatments, whereas a significant impact of Digestate was only observed in

506 juveniles when digestate was applied at the highest rate (R300, i.e. $300 \mathrm{~kg} \mathrm{~N}^{-}$

$507{ }^{1}$ eq.). While this volume exceeds common practice under agronomic decisions, the

508 surfacing of earthworms and survival have also been reported from a field

509 experiment receiving the rate equivalent to $70 \mathrm{~kg} \mathrm{~N} \mathrm{ha}^{-1}$ (personal communication

510 with Amy Watkins, Sustainability Project Manager, Agrii agronomy services, UK,

511 2020), with mixed effects reported in other studies (Koblenz et al., 2015; WRAP,

512 2015; Sizmur et al., 2017). For example, A. chlorotica was not found in one site

513 that received $160 \mathrm{~kg} \mathrm{~N} \mathrm{ha}^{-1}$ eq. of digestate, and at another site it accounted for

514 only $6.1 \%$ out of the five species found when digestate was applied at $130 \mathrm{~kg} \mathrm{~N}$

515 ha $^{-1}$ eq. (Koblenz et al., 2015). In another study, Lumbricus terrestris biomass only

516 increased when digestate was applied with cereal straw but declined by $23 \%$ when

517 digestate was applied alone (Sizmur et al., 2017). In contrast, the impact on the

518 abundance of endogeics was site dependent (WRAP, 2015). 
519 The variability of negative responses to salts by both adults and juveniles in this

520 study may be explained by horizontal stratification of earthworm communities

521 within the soil. Earthworms closer to the soil surface would be exposed to greater

522 concentrations of salts that likely increased mortality. Earthworms deeper in the

523 soil were exposed to less salts due to the dilution gradients that formed as the

524 salts leached through the soil profile. Toxicity response by the two stages could be

525 elucidated in further studies looking at the effect of horizontal stratification and

526 whether juveniles and adults burrowing and/or emergence behaviour is different

527 when exposed to adverse conditions.

528 A small number of earthworms emerged to the soil surface soon after applying

529 Digestate, Osmotic-Stress and Synthetic-Digestate treatments (Table 2). The few

530 that emerged died soon after surfacing. These treatments had significantly higher

531 concentrations of $\mathrm{Na}$ and $\mathrm{K}$ salt ions and EC (Fig. 3 and 4), this observation may

532 have been biased by unequal distribution of earthworms through the soil profiles of

533 the different treatments.

534 Reaction time to external stimuli. i.e. salts dissociated in soil pore water, is

535 dependent on the internal osmotic pressure of the earthworm (Parker and Metcalf,

536 1906; Laverack, 1960). In this experiment, treatment stimuli only resulted in a few

537 earthworms surfacing (Table 2). Reaction times to being exposed to $\mathrm{NaCl}$ or $\mathrm{KCl}$

538 solutions can be species dependent. For example, Allolobophora foetida (Savigny,

539 1826) (accepted as Eisenia fetida (Savigny in Cuvier, 1826)) can react 200 times

540 faster to stimuli than Helodrilus sp., and response to $\mathrm{KCl}$ being 7.5 times faster

541 than to $\mathrm{NaCl}$. However, the authors observed biomass loss across both ecotypes

542 (Parker and Metcalf, 1906). The earthworms' body membrane is selective and

543 prevents salt molecules (i.e. $\mathrm{CaCl}_{2}, \mathrm{NaCl}$ or $\mathrm{KCl}$ ) from crossing freely (Laverack,

544 1963; Edwards and Lofty, 2013). Chloride was not measured in this study, but it is 
545 unlikely that significant concentrations would be detected at the end of the trial. Its

546 anionic properties limits persistence in pore water due to soil's relatively low anion

547 exchange capacity and so concentration would decrease rapidly post application

548 (Parfitt, 1979).

549 The treatments Digestate, Osmotic-Stress and Synthetic-Digestate each had a

550 negative effect on the survival and biomass of $A$. chlorotica when applied at the

551 higher rate, R300. However, the Water control also had a similar effect on the

552 adults. These results suggest that the mechanisms behind treatment toxicity could

553 not be fully elucidated even though a significant treatment effect was observed. In

554 the conditions used in this study, the application of water alone was sufficient to

555 increase adult mortality. This suggests that the water filled pore space increased

556 to such an extent that anaerobic conditions occurred in the soil. Repeating the

557 experiment with a different soil moisture regime, a different soil texture, or with

558 different proportion of $A$. chlorotica morphs or earthworm species may have led to

559 different results. For example, the A. chlorotica green morph is more tolerant of

560 high moisture content soils than the pale morph (Satchell, 1967). Nevertheless,

561 these results highlight the issue of applying liquid soil amendments to soil with a

562 high moisture content (e.g. $60 \%$ WFPS). This could be detrimental to the soil

563 biota, even if the non-water fraction of the amendment itself is harmless.

564 Biomass loss was observed for all treatments at both rates, R150 and R300, and

565 including the Water control, which suggests that osmotic stress, due to the

566 concentrations of salts, was not the only cause of death. The earthworm's

567 semipermeable membrane allows the passage of water from a hypotonic solution

568 to a hypertonic one. If internal body fluids have lower concentration of salts (i.e. is

569 hypotonic) compared to the external (hypertonic) environment when initially

570 exposed to the Digestate, Osmotic-Stress and Synthetic-Digestate treatments, 
571 then internal water would pass from the earthworm to the soil causing weight loss.

572 This is because earthworm's biomass is generally about $80 \%$ water (Laverack,

573 1963). However, for the Labile-C and Water control treatments other factors were

574 at play.

575 Exchangeable concentrations of ions were analysed in this study because the use

576 of total concentrations of metals in soil are not suited to ecotoxicology studies;

577 totals do not reflect ion bioavailability (Rowell, 1994). Higher concentrations of a

578 cation in pore water, such as $\mathrm{Ca}^{2+}$, can reduce bioaccumulation of another cation

579 in Lumbricidae (Lee and Kim, 2008). However, the buffering effect of $\mathrm{Ca}^{2+}$ in this

580 study was unlikely because no significant differences in bioavailable Ca were

581 found in soil across all treatments applied at either rate (R150 or R300).

582 The bioavailability of toxicants can also be reduced by phosphate $\left(\mathrm{PO}_{4}{ }^{3-}\right)$ because

583 it competes for cellular transport carriers (Lee and Kim, 2008). In our study, the

584 Osmotic-Stress R300 treatment had lower concentration of bioavailable P in

585 comparison with soil conditions before and after other treatments were applied,

586 which could be due to carrier competition between bioavailable $\mathrm{P}$ and ions applied

587 with the treatment. Phosphate may play a significant role in preventing toxicity if

588 the earthworms' osmotic balance remains uncompromised.

589 Earthworms' behaviour was not visually inspected throughout experiment to

590 assess whether good health had been maintained. However, earthworms were

591 checked for healthy cues such as turgidity, body shape and uncompromised

592 epidermal membrane, and mobility before being added to experimental boxes

593 (Frund et al., 2010). The biomass decline of $A$. chlorotica across all treatments

594 implies that feeding slowed or ceased during the experiment (Fig. 1), which could

595 have led to starvation. Therefore, an internal buffering effect through ingesting

596 Digestate or Synthetic-Digestate (which are rich in organo-compounds) is unlikely. 
597 Uptake of hydrophobic organo-compounds mostly occurs by feeding on soil (Ma et

598 al., 1998) and metal toxicity is reduced by such compounds because they do not

599 readily dissociate in solution and can form organometallic compounds (Artuso et

600 al., 2011). Biomass decline across all treatments, e.g. reduced internal water due

601 to osmotic stress and/or aestivation, was a likely caused by the disruption of

602 homeostatic mechanisms. Earthworms can stop feeding in response to sensory

603 stimuli that activate chemoreceptors in their body membrane. Allolobophora spp.

604 are sensitive to stimuli of salts and sugars origin (sucrose and glycerol) (Laverack,

605 1960), which supports this hypothesised mechanism. It is possible that the

606 earthworms were stressed throughout the experiment due to the maintenance of

607 the pots at $60 \%$ WFPS, which may have been too high. Similar experiments

608 should aim to use of a range of WFPS to provide insights into this potential bias.

609 If adverse conditions persist, $A$. chlorotica become incapable of regulating the

610 uptake of water and salts (Laverack, 1963). In clayey soils, it was found that $A$.

611 chlorotica coiled up at $13.5 \%$ gravimetric soil water content ( $34 \%$ WFPS)

612 (Evans and Guild, 1948). Coiling is associated with aestivation, a period of

613 inactivity induced by adverse conditions or seasonal adaptations (Sims and

614 Gerard, 1999). Therefore, maintaining the soil at $60 \%$ WFPS, for experimental

615 purposes, could have induced aestivation and various fractions of WFPS should

616 be considered if using $A$. chlorotica pale morph in subsequent experiments.

617 The decline in the number of adults for all treatments applied at the higher rate

618 R300, except for the Labile-C treatment (Fig. 2), suggests that the excretory and

619 osmoregulatory system was compromised. Various factors could have provoked

620 mortality and the salts in the Osmotic-Stress and Synthetic-Digestate are the most

621 likely explanation for those treatments. However, mortality in the other treatments

622 could have been caused by temporary anaerobic or anoxic conditions, and by the 
623 accumulation of nitrogenous waste compounds (Roots, 1956; Laverack, 1963;

624 Möller and Müller, 2012; Edwards and Lofty, 2013).

625 The Water control R300 treatment is likely to have increased the volume of water

626 in soil pore space. Water immersion may not be lethal to earthworms providing

627 that toxic or noxious products do not accumulate over extensive periods and/or

628 there is no depletion of oxygen (Laverack, 1963; Edwards and Lofty, 2013).

629 However, water saturated soil reduces available oxygen within the pore space,

630 preventing critical respiration processes to take place (Abe and Buck, 1985). The

631 observed negative effects in the water control may be explained by oxygen

632 depletion. The accumulation of noxious products, i.e. nitrogenous compounds,

633 may also explain observed negative effects for both adults and juveniles in the

634 Synthetic-Digestate R300 treatment. Total-N was significantly greater in Synthetic-

635 Digestate R300 compared to Water control R300 treatment. It was also greater in

636 the Digestate and Osmotic-Stress treatments, but not significantly different.

637 Whereas it declined in the Labile-C treatment. These findings could suggest that

638 there was an accumulation of nitrogenous compounds from dead biomass in the

639 former and volatilisation of ammonium through the breakdown of glutamic acid in

640 the Labile-C treatment in the latter.

641 The adults were the most affected by treatments applied at both rates (Fig. 2). For

642 example, there was a decline in the number of individuals for the Digestate and

643 Osmotic-Stress treatments applied at both rates (R150 and R300). A decline was

644 also detected with Synthetic-Digestate and Water R300 treatments. The

645 earthworms' tubular body shape provides it with a large surface area-to-volume

646 ratio, necessary for gas exchange. Smaller earthworms, like juveniles, have

647 greater surface:volume ratio, which permits higher diffusion rates to occur as those

648 of osmotic processes. For example, processes such as exchange of metal ions 
649 (i.e. $\mathrm{Na}, \mathrm{K}, \mathrm{Ca}$ and $\mathrm{Mg}$ ), $\mathrm{O}_{2}$ and $\mathrm{CO}_{2}$ gases. A. chlorotica's short and stout

650 morphology allows it to thrive in the rhizosphere, with juveniles having fewer

651 segments than the adults (Piearce, 1983). The shorter length of the juveniles, but

652 greater surface:volume ratio could mean that exposure to treatments is reduced

653 because diffusion rates across their semipermeable is higher leading to the

654 balancing of in- and out-ward flow that offers protection from the toxic effects of

655 treatments. Helodrilus oculatus is a long and thin endogeic earthworm and it has a

656 large surface:volume ratio (Dobson and Satchell, 1956). Their morphology is

657 advantageous in low oxygenated habitats because their surface area permits

658 diffusion to continue and thrive in such environments (Dobson and Satchell, 1956).

659 This sort of morphological variations could explain the different response observed

660 between the juveniles and adults. Adults being longer and stouter means that

661 diffusion processes occur at a lower rate, potentially increasing toxicity exposure.

662 However, further studies are required to determine whether the surface:volume

663 ratio is a factor affecting toxicity response by the two development stages.

664 Our results suggest that there could have been a buffering effect from Synthetic-

665 Digestate R150 and Labile-C R300, which could have reduced adult mortality in

666 these treatments (Fig. 2). Cuticle permeability and osmotic potential are likely to

667 have caused an imbalance in diffusion rates across treatments, meaning that the

668 inward flow exceeded excretion rates. Soil amendments rich in organo-compounds

669 can reduced the capacity of a soil to conduct (i.e. EC). Conductivity is affected by

670 many soil properties including soil organic matter and salinity. Organo-

671 amendments have chelating properties due to their charged properties (i.e.

672 carboxylate salts, -COO-), leading to charged sites binding with cations and

673 leaving them in an inactive state (Chehab et al., 2020). Glucose and starch,

674 components of Synthetic-Digestate and Labile-C, have high sorption (binding) 
675 capability and can form chemical complexes (Polaczek et al., 2000). In this study,

676 EC was found to be a poor predictor of the response of earthworms to treatments.

677 For example, EC was lower in the Water control treatment than in the Digestate,

678 Osmotic-Stress or Synthetic-Digestate applied at either rate, R150 or R300 (Fig. 3

679 and 4). However, the survival of adults was lower in all four treatments in

680 comparison with Labile-C (Fig. 2). It has been suggested that the nature of salts is

681 more important than EC in forecasting potential impacts on earthworm survival

682 (Owojori and Reinecke, 2014). This demonstrates the importance of knowing the

683 chemical composition of digestates to be able to make effective predictions as to

684 their likely impacts on earthworms and the soil biota.

685

688 This study demonstrates that digestate can cause increased mortality of $A$.

689 chlorotica. However, the experimental setup was not conducive to earthworm

690 survival, although it was not unrealistic for field conditions. A combination of

691 different factors may have explained the variable mortality rates amongst

692 earthworms. Those factors could have been: Horizontal stratification through the

693 soil profile; the application of high-water content amendments or just water to soils

694 that are already wet; greater surface:volume ratio in the juveniles; disruption of the

695 homeostatic mechanism that prevented organometallic compounds from forming

696 and decrease toxicity.

697 This study is important because digestate is applied in agricultural systems as a

698 soil amendment but its impact on soil biology is not fully understood. It is unlikely

699 that the volume of digestate used in this study would be applied in one rate under

700 agronomic decisions. Moreover, the application of AD digestate at a rate of $300 \mathrm{~kg}$

$701 \mathrm{~N} \mathrm{ha}^{-1}$ is not permitted in the UK within one crop season (Defra, 2010). 
702 Nevertheless, the intention of this work was to determine a potential mechanism

703 behind the negative effects being reported on earthworm survival after the

704 application of AD digestate.

705 Other limitations with this study are that only one earthworm species and soil type

706 was used. This preliminary study could be used to develop further work, with some

707 focus on manipulating soil water content, soil texture and depth effect, and

708 earthworms' diet prior to experiment. It has established a baseline from which, as

709 far as we know, is missing from research. Habitat conditions of $A$. chlorotica were

710 replicated in terms of soil type, depth, and area to closely resemble field conditions

711 and reduce experimental constraints. It provides an insight into ecotoxicology

712 research looking at the impacts of digestate on a wild earthworm, which can

713 dominate earthworm samples from agricultural systems, as does $A$. chlorotica in

714 the UK.

715

$716 \quad 6$. Funding

717 This work was supported by the European Union's Horizon 2020 research and

718 innovation programme [grant agreement No 690142, 2016]. Financial support has

719 been the sole role of the sponsor.

720 7. Acknowledgements

721 The authors would like to thank Mr Andrew P. Cooley and Mr Kevin Jones for their

722 demonstration work on analytical techniques of chemical analyses, and Dr Lucy

723 Crockford on BOD analysis.

8. References

725

726 Abe, A. S. and Buck, N. (1985). Oxygen uptake of active and aestivating

727 earthworm Glosso scolex paulistus (Oligochaeta, Glossoscolecidae), Comparative

728 Biochemistry and Physiology, 81A(1), pp. 63-66. 
729 Artuso, N., Kennedy, T. F., Connery, J., Grant, J. and Schmidt, O. (2011). Effects

730 of Biosolids at Varying Rates on Earthworms (Eisenia fetida) and Springtails

731 (Folsomia candida), Applied and Environmental Soil Science, 2011, pp. 1-10.

732 Bates, D., Mächler, M., Bolker, B. and Walker, S. (2015). Fitting Linear Mixed-

733 Effects Models Using Ime4, Journal of Statistical Software, 67(1), 1-48.

734 Blouina, M., Hodsonb, M. E., Delgado, E. A., Baker, G., Brussaard, L., Butt, K. R.,

735 Dai, J., Dendoovenh, L., Peresi, G., Tondohj, J. E., Cluzeauk, D. and Brun, J.- J.

736 (2013). A review of earthworm impact on soil function and ecosystem services,

737 European Journal of Soil Science, 64, pp. 161-182.

738 Butt, K. R. and Lowe, C. N. (2011). Controlled Cultivation of Endogeic and Anecic

739 Earthworms, in Karaca, A. (ed.). Biology of Earthworms, Soil Biology 24. Berlin:

740 Springer-Verlag Berlin Heidelberg, pp. 107-121.

741 Chehab, H., Tekaya, M., Hajlaoui, H., Abdelhamid, S., Gouiaa, M., Sfina, H.,

742 Chihaoui, B., Boujnah, D. and Mechri, B. (2020). Complementary irrigation with

743 saline water and soil organic amendments modified soil salinity, leaf $\mathrm{Na}^{+}$,

744 productivity and oil phenols of olive trees (cv. Chemlali) grown under semiarid

745 conditions, Agricultural Water Management. Elsevier, 237, p. 106183.

746 Corden, C., Bougas, K., Cunningham, E., Tyrer, D., Kreibig, J., Zettl, E., Gamero,

747 E., Wildey, R. and Crookes, M. (2019). Digestate and compost as fertilisers: Risk

748 assessment and risk management options. Edited by $\mathrm{V}$. Bertato. European

749 Commission, Directorate General - Environment, Brussels, 463pp.

750 Defra (2010). Fertiliser Manual RB209, p. 257.

751 Dobson, R. M. and Satchell, J. E. (1956). Eophila oculata at Verulamium: a

752 Roman Earthworm Population? Nature, 177, pp. 796-797. 
753 Edwards, C. A. and Lofty, J. R. (2013). Biology of Earthworms. Springer.

754 Evans, A. C. and Guild, W. J. M. L. (1948). Studies on the Relationships Between

755 Earthworms and Soil Fertility: IV. On the Life Cycles of Some British Lumbricidae,

756 Annals of Applied Biology, 35(4), pp. 471-484.

757 Fox, J. and Weisberg, S. (2019). An R Companion to Applied Regression, Third

758 edition. Sage, Thousand Oaks CA.

759 Fründ, H. C., Butt, K., Capowiez, Y., Eisenhauer, N., Emmerling, C., Ernst, G.,

760 Potthoff, M., Schädler, M. and Schrader, S. (2010). Using earthworms as model

761 organisms in the laboratory: Recommendations for experimental implementations,

762 Pedobiologia, 53, pp. 119-125.

763 Huber, S., Prokop, G., Arrouays, D., Banko, G., Bispo, A., Jones, R.J.A.,

764 Kibblewhite, M.G., Lexer, W., Möller, A., Rickson, R.J., Shishkov, T., Stephens,

765 M., Toth, G., Van den Akker, J.J.H., Varallyay, G., Verheijen, F.G.A. and Jones,

766 A.R. (2008). Environmental Assessment of Soil for Monitoring: Volume I Indicators

767 \& Criteria. EUR 23490 EN/1, Office for the Official Publications of the European

768 Communities, Luxembourg, 339pp.

769 Jones, D. T. and Eggleton, P. (2014). Earthworms in England: distribution,

770 abundance and habitats. Edited by D. Sheppard. Natural England, Exeter, 19pp.

771 Kavdir, Y. and llay, Y. (2011). Earthworms and soil structure, in Karaca, A. (ed.).

772 Soil biology: biology of earthworms. Berlin: Springer Berlin Heidelberg, pp. 39-40.

773 Koblenz, B., Tischer, S., Rücknagel, J. and Christen, O. (2015). Influence of

774 biogas digestate on density, biomass and community composition of earthworms,

775 Industrial Crops and Products, 66, pp. 206-209. 
776 Laverack, M. S. (1960). Tactile and chemical perception in earthworms -I.

777 Responses to touch, sodium chloride, quinine and sugars, Comparative

778 Biochemistry and Physiology, 1(2).

779 Laverack, M. S. (1963). The physiology of earthworms. Edited by G. A. Kerkut.

780 Oxford: Pergamon Press.

781 Lee, K. E. (1985). Earthworms: their ecology and relationships with soils and land 782 use. London: Academic Press.

783 Lee, B. T. and Kim, K. W. (2008). Arsenic accumulation and toxicity in the

784 earthworm Eisenia fetida affected by chloride and phosphate, Environmental

785 Toxicology and Chemistry, 27(12), pp. 2488-2495.

786 Lubbers, I. M. and van Groenigen, J. W. (2013). A simple and effective method to

787 keep earthworms confined to open-top mesocosms, Applied Soil Ecology, 64, pp.

$788 \quad 190-193$.

789 Ma, W. C., van Kleunen, A., Immerzeel, J. and de Maagd, P. Gert-Jan (1998).

790 Bioaccumulation of polycyclic aromatic hydrocarbons by earthworms: Assessment

791 of equilibrium partitioning theory in in situ studies and water experiments,

792 Environmental Toxicology and Chemistry, 17(9), pp. 1730-1737.

793 MAFF/ADAS (1986). The analysis of agricultural materials RB427. 3rd ed. London:

794 HMSO publications.

795 Möller, K., Müller, T., 2012. Effects of anaerobic digestion on digestate nutrient

796 availability and crop growth: A review: Digestate nutrient availability. Engineering

797 in Life Sciences, 12, pp. 242-257. 
798 Möller, K. (2015). Effects of anaerobic digestion on soil carbon and nitrogen

799 turnover, $\mathrm{N}$ emissions, and soil biological activity. A review, Agronomy for

800 Sustainable Development, 35, pp. 1021-1041.

801 Oksanen, J., Blanchet, F.G., Friendly, M., Kindt, R., Legendre, P., McGlinn, D.,

802 Minchin, P.R., O'Hara, R.B., Simpson, G.L., Solymos, P., Stevens, M.H.H., S.,

803 Eduard and Wagner, Helene (2019). vegan: Community Ecology Package. R

804 package version 2.5-6.

805 Owojori, O. J. and Reinecke, A. J. (2014). Differences in ionic properties of salts

806 affect saline toxicity to the earthworm Eisenia fetida, Applied Soil Ecology, 83, pp.

$807 \quad 247-252$.

808 Parfitt, R. L. (1979). Anion adsorption by soils and soil materials, Advances in

809 Agronomy, 30(C), pp. 1-50.

810 Parker, G. H. and Metcalf, C. R. (1906). The reactions of earthworms to salts: a

811 study in protoplasmic stimulation as a basis of interpreting the sense of taste,

812 American Journal of Physiology-Legacy Content, 17(1), pp. 55-74.

813 Piearce, T. G. (1983). Functional morphology of lumbricid earthworms, with

814 special reference to locomotion, Journal of Natural History, 17, pp. 95-111.

815 Polaczek, E., Starzyk, F., Maleńki, K. and Tomasik, P. (2000). Inclusion

816 complexes of starches with hydrocarbons, Carbohydrate Polymers, 43(3), pp.

$817 \quad 291-297$.

818 R Core Team (2019). R: A language and environment for statistical computing. R

819 Foundation for Statistical Computing, Vienna, Austria. https://www.R-project.org/

820 Ritz, K., Black, Helaina I.J., Campbell, Colin D., Harris, Jim A., Wood, Claire

821 (2009). Selecting biological indicators for monitoring soils: A framework for 
822 balancing scientific and technical opinion to assist policy development. Ecological

823 Indicators, 9, pp. 1212-1221.

824 Roots, B. I. (1956). The Water Relations of Earthworms: II. Resistance to

825 Desiccation and Immersion, and Behaviour When Submerged and When Allowed

826 a Choice of Environment, Journal of Experimental Biology, 33(1), pp. 29-44.

827 Rowell, D. L. (1994). Soil Science: Methods and Applications. Harlow, Essex:

828 Pearson Education Ltd.

829 Mangiafico, S.S. (2016). Summary and Analysis of Extension Program Evaluation 830 in R, version 1.18.1.

831 Satchell, J. E. (1967). Colour Dimorphism in Allolobophora chlorotica Sav.

832 (Lumbricidae)., Journal of Animal Ecology, 36(3)., pp. 623-630.

833 Sims, R. W. and Gerard, B. M. (1999). Earthworms. Edited by R. S. K. Barnes and

834 J. H. Crothers. Shrewsbury: Field Studies Council.

835 Sizmur, T. and Hodson, M. E. (2009). Do earthworms impact metal mobility and

836 availability in soil? - A review, Environmental Pollution, 157, pp. 1981-1989.

837 Sizmur, T., Martin, E., Wagner, K., Parmentier, E., Watts, C. and Whitmore, A. P. 838 (2017). Milled cereal straw accelerates earthworm (Lumbricus terrestris). growth

839 more than selected organic amendments, Applied Soil Ecology, 113, pp. 166-177.

840 Taylor, M., Rollett, A. and Chambers, B. (2011). Compost \& Anaerobic Digestate

841 Quality for Welsh Agriculture. Edited by D. Tompkins. WRAP Cymru, 135pp.

842 Van-Camp. L., Bujarrabal, B., Gentile, A-R., Jones, R.J.A., Montanarella, L.,

843 Olazabal, C. and Selvaradjou, S-K. (2004). Reports of the Technical Working

844 Groups Established under the Thematic Strategy for Soil Protection. EUR 21319 
845 EN/3. Office for Official Publications of the European Communities, Luxembourg, 846 872pp.

847 Venables, W.N. and Ripley, B.D. (2002). Modern Applied Statistics with S, Fourth

848 edition. Springer, New York. ISBN 0-387-95457-0

849 Vos, H. M. J., Ros, M. B. H., Koopmans, G. F. and van Groenigen, Jan Willem 850 (2014). Do earthworms affect phosphorus availability to grass? A pot experiment, 851 Soil Biology \& Biochemistry, 79, pp. 34-42.

852 Environment Agency (EA) and WRAP (Waste \& Resources Action Programme).

853 (2014). Anaerobic Digestate: Quality Protocol. Environment Agency, 29pp.

854 Wallace, P. Contributors: Frederickson, J., Chambers, B., Taylor, M., Longhurst,

855 P., Tyrrell, S., Gale, P., Goddard, A. and Litterick, A. (2011). Digestates: Realising

856 the fertiliser benefits for crops and grassland. WRAP, 18pp.

857 Wickham, H., François, R., Henry, L. and Müller, K. (2020). dplyr: A Grammar of 858 Data Manipulation. R package version 1.0.2.

859 WRAP (2015). DC-Agri; field Experiments for Quality Digestate and Compost in 860 Agriculture, WP1 report Appendices, Prepared by: Bhogal, Anne; Taylor, Matthew; 861 Nicholson, Fiona; Rollett, Alison; Williams, John; Price, Paul Newell; Chambers, 862 Brian; Litterick, Audrey; Whittingham, Mark. 200pp 